1

\title{
1 A longitudinal study of $E$. coli lineages and antimicrobial resistance in Ecuadorian \\ 2 children
}

3

4 Diana Calderón, ${ }^{\mathrm{a}}$ Paúl A. Cárdenas, ${ }^{\mathrm{a}}$ Jay Graham, ${ }^{\mathrm{b}}$ Gabriel Trueba ${ }^{\text {a\# }}$

5

$6 \quad{ }^{a}$ Microbiology Institute, Universidad San Francisco de Quito

$7 \quad{ }^{\mathrm{b}}$ Environmental Health Sciences Division, University of California, Berkeley,

8 California, USA

9

10 Running Head: Turnover of antimicrobial-resistant E. coli lineages

\#Address correspondence to Gabriel Trueba, gtrueba@usfq.edu.ec

Abstract word count: 112

Text word count: 
2

\section{ABSTRACT}

22 The gastrointestinal tract (GIT) constitutes a complex and diverse ecosystem.

23 Escherichia coli is one of the most frequently studied and characterized species in the

24 gut ecosystem. Nevertheless, there has been little research to determine their diversity and population dynamics in the intestines of children over time. Many intestinal E. coli lineages carry antimicrobial resistance and virulence genes, which have implications in disease and public health. In this one-year prospective study, a fresh fecal sample was obtained from 30 children longitudinally for one year ( $n=82$ fecal samples). From each stool sample, five Escherichia coli colonies were randomly selected to characterize their genotype and phenotypic antimicrobial resistance pattern $(n=405$ E. coli isolates). We found that the most numerically dominant $E$. coli lineages in children's intestines were transient colonizers, and phenotypic antimicrobial resistance varied significantly over time, however, ST131 a multi-drug resistant pathogen, and 3 additional STs persisted in a child's intestine for 3 months or more.

\section{IMPORTANCE}

The length of residency and numeric dominance of antimicrobial-resistant E. coli may affect the extent to which an isolate contributes to the dissemination of antimicrobial resistance. We studied the persistence of numerically dominant and antimicrobialresistant lineages of $E$. coli in the human intestine and found that $E$. coli lineages in the gut of children change rapidly over time. 
3

42

43

44

45

\section{INTRODUCTION}

Escherichia coli is a minor component of the intestinal microbiota of warm-blooded animals (1, 4, and 11). Within the human gut and other warm-blooded animals, there are more than 10 different lineages of $E$. coli at any time; each of these lineages is present in different abundances and remains in the intestine for different periods.

Intestinal E. coli could be classified as a resident when they remain in the intestine for months and even years (6), transient when they remain for days or weeks (6); dominant when the isolates make up a large proportion (>50\%) (26) of the E. coli cells in the intestine, and minority when the proportion is smaller $(<10 \%)(51)$.

Some E. coli are a source of problematic antimicrobial resistance genes (ARGs) (4, 21, and 29) and certain $E$. coli lineages are a major cause of diseases $(36,37$, and 38). The abundance of a pathogenic $E$. coli lineage in the intestine has been suggested to be a critical risk factor for intestinal disease (54). Similarly, the abundance of AMR E. coli and its persistence in the intestine could be critical in the dissemination of ARGs; $E$. coli is probably the intestinal species that can be transmitted the most between hosts (21, 30 and 34) and it is very active in horizontal gene transfer of ARGs (5, 35 and 37). Here we screened the dominant $E$. coli strains obtained from children less than five years of age and analyzed the turnover of these strains every 3 months for one year.

Dominant $E$. coli were defined as the $E$. coli colonies that grew on MacConkey agar at the highest numbers (26).

\section{RESULTS}

We followed over one year a total of 30 children: 8 children with two sampling points (SP I and SP II), and 22 children with three sampling points (SP I, SP II, and SP III). We analyzed 405 E. coli isolates from 82 fecal samples from 30 individuals. The large 
4

majority of fecal samples $(81.71 \%)$ contained one or 2 dominant $E$. coli isolates (isolates carrying 1 or 2 different fumC alleles) ( Table S1 and Table S2). When we analyzed the diversity of all the isolates, we found that $64 \%$ of fecal samples contained isolates with the same fumC alleles: $34 \%$ of fecal samples had isolates with the fumC11 allele, 11 (13\%) fecal samples had isolates with fumC35 and 9 (11\%) fecal samples had isolates with fumC4 allele. Among the 405 isolates, we found a total of 41 fumC alleles; the most prevalent was fumC11 ( $\mathrm{n}=108,26.7 \%)$, followed by fum $C 35(\mathrm{n}=40$, 9.8\%) and fum $C 4(\mathrm{n}=38,9.4 \%)$. We found only 4 individuals who carried isolates of the same ST in fecal samples: ST34 was the predominant genotype recovered from one child (Child \#26, isolates recovered 11 months apart), ST10 was the predominant genotype in two children (Child \#20, isolates recovered 7 months apart) and (Child \# 30, isolates recovered 5 months apart), and ST131 was the predominant genotype in one child (Child \#23, isolates recovered 4 months apart) (Fig. 1).

Among the 405 isolates recovered, 122 (30.1\%) were susceptible to all the antimicrobials tested. The remaining fell into one of the 76 unique antibiotic resistance profiles: 50 isolates $(12.3 \%)$ were resistant to only one antibiotic, 37 isolates $(9.1 \%)$ were resistant to two antibiotics, and 196 (48.4\%) were resistant to three or more antimicrobials.

Phenotypic resistance to the combination of Ampicillin (AM), Trimethoprimsulfamethoxazole (SXT), and Tetracycline (TE) was the most common profile $(\mathrm{n}=36$, 8.9\%), followed by Tetracycline (TE) resistance ( $\mathrm{n}=21,5.2 \%)$ and Ampicillin (AM), Trimethoprim-sulfamethoxazole (SXT), and Amoxicillin-clavulanic acid (AMC) resistance $(n=15,3.7 \%)$.

Among the eight children who were enrolled for SP I and SP II, the highest percentages of resistance in SP I isolates was to Tetracycline (TE) (50\%), Trimethoprim- 
5

91 sulfamethoxazole (SXT) (37.5\%), and Ampicillin (AM) (35\%), while in SP II isolates was to Ampicillin (AM) (54.3\%), Trimethoprim-sulfamethoxazole (SXT) (40\%) and

Tetracycline (TE) (31.4\%). There were significant statistical differences in the I (Table 1 and Table S3).

Among SP I - SP III, which included 22 children, the highest percentages of resistance in SP I and SP II isolates corresponded to Ampicillin (AM) (SP I=58.2\% and SP $\mathrm{II}=54.5 \%)$, Trimethoprim-sulfamethoxazole (SXT) (SP I and SP II=52.7\%) and Tetracycline (TE) (SP I=50\% and SP II=47.3\%), while in SP III isolates were to Trimethoprim-sulfamethoxazole (SXT) (45.4\%), Tetracycline (TE) (45.4\%) and Ampicillin (41.8\%) (Table 1 and Table S3).

\section{DISCUSSION}

During the current prospective study, we followed 30 children for 2 to 3 sampling periods (for 1 year) and screened the numerically dominant $E$. coli strains present in fresh fecal samples. At least three of the five selected colonies from each sample showed the same fumC allele and the same antimicrobial resistance profile, providing additional evidence that the isolates were numerically dominant in the individual (Figure 1). We observed that very few strains $(n=4)$ persisted over time in some individuals, suggesting that most numerically dominant strains are transient colonizers and that there is a high turnover rate of $E$. coli lineages. This observation is in agreement with previous reports showing a high diversity and high turnover rate of $E$. coli lineages in the human intestines $[10,18,53]$. The high turnover rate may be due to bacteriophage, bactericins, protozoal predation, or immune mechanisms $[4,10]$. 
6

115 Recent evidence has indicated that diet can also favor the proliferation of some strains

116 of other intestinal bacteria [35]. We identified only four children with possible dominant

117 resident strains (i.e. strains that persisted throughout the study period): ST10

118 (individuals 20 and 30), ST34 (individual 26), and ST131(individual 23), isolates which

119 persisted for $7,5,11$, and 4 months, respectively. The most remarkable of them is

120 ST131 which is a known human extra-intestinal pathogen, characterized by its virulence

121 (37) and resistance to extended-spectrum cephalosporins (ESC) and fluoroquinolones

122 (FQ) (37 and 39). This ST is strongly related to extra-intestinal infections, mainly

urinary tract (10 and 13) which has been reported as dominant in human intestines (53),

domestic animals intestine the environment (36 -39). Moreover, ST10 and ST34

belonged to clonal complex 10 (CC10); ST10 is known as one of the most dominant commensal STs in Escherichia coli (38), however, strains belonging to this ST are often not clonal (40).

According to the surveys, 30 households reported access to potable water 24/7, and 28 had sewerage. During the sampling periods, 20 children changed their dietary habits (stop breastfeeding), 14 children were exposed to antimicrobials at least in one sampling period, and 29 had contact with domestic animals (pets, livestock, poultry, etc.), and 14 children had diarrhea at least in one sampling period. These events may have altered the frequency of some of the E. coli lineages, however, it is difficult to assess their impact (45).

Regarding phenotypic antimicrobial resistance, among the 405 isolates analyzed, $30.1 \%$ (122 of 405) were susceptible to all of the antimicrobials tested. Resistance to Ampicillin (AM), Trimethoprim-sulfamethoxazole (SXT), and Tetracycline (TE) were the most prevalent, while Gentamycin (GM) was the least because only six strains showed resistance. We found several commensal Escherichia coli isolates resistant to 
Imipenem (IPM) (24 out of 405, 5.9\%) and Cefepime (FEP) (40 out of 405, 9.8\%)

which are resistances that should be associated with hospitals and not community isolates (41).

There were significant statistical differences in resistance to Ampicillin (AM) between

SP I and SP II ( $\mathrm{p}=0.004$, Table 1), and resistance to Ampicillin (AM), Ceftazidime

(CAZ), Ciprofloxacin (CIP), and Amoxicillin + clavulanic acid (AMC) was are potentially not that useful because the phenotypic resistance profiles change rapidly over time, without any strong driving factors. Understanding the factors involved in lineage turnover is critically important for understanding antimicrobial resistance and virulence gene carriage in commensal strains.

152 Our research shows another level of complexity on the understanding of the gut microbiome, which is important as many strains of the same species carry different metabolic, virulence, or antibiotic resistance genes. Our study reinforces the idea of the constant transition of microbiome members over time $[4,5,11,12$, and 19] and the need for more research in the dynamics of strain populations in the intestine.

\section{MATERIALS AND METHODS}

Study locations. This one-year longitudinal study was carried out in six semi-rural 
8

consent was provided by the primary childcare provider. Sixty-one households were enrolled at the beginning of the study but, only 27 finished the full longitudinal study.

Ethical considerations. The study protocol was approved by the Committee for Protection of Human Subjects (CPHS) and the Office for Protection of Human Subjects (OPHS) at the University of California, Berkeley (Federalwide Assurance \# 6252), the Human Research Ethics Committee at the Universidad San Francisco de Quito (no. 2017-178M) and the Ministry of Public Health, Ecuador (MSPCURI000243-3).

Sample collection. We collected a single fecal sample from each child during three sampling periods (SP): from October to December of 2018 (SP I), from January to May of 2019 (SP II), and from July to December of 2019 (SP III), obtaining a total of 120 stool samples. Each time a sample was collected, the childcare provider completed a survey related to the current family lifestyle and recent exposure-related factors relevant to AMR. Eighty-one stool samples were obtained from the same 27 children along the three sampling periods. Moreover, a total of 10 fecal samples were obtained from the same five children in the sampling periods I and II. The remaining 29 stool samples were obtained only during sampling period I; therefore, those samples were discarded for further analyses. Each stool sample was collected into sterile tubes, stored at $4^{\circ} \mathrm{C}$, transported to the laboratory, and immediately processed.

Escherichia coli isolation. Each fecal sample was plated on MacConkey agar and incubated at $37^{\circ} \mathrm{C}$ for 18 hours. To ensure the selection of the dominant Escherichia coli strain ( $\geq 50 \%$ of all colonies) [26], we collected 5 colonies that correlated with the predominant colony morphology. Additionally, each colony was transferred to Chromocult ${ }^{\circledR}$ coliform agar for the identification of Escherichia coli through its $\beta$-Dglucuronidase activity. Those strains were incubated in Brain Heart Infusion (BHI) 
9

medium + glycerol $(15 \%)$ at $37^{\circ} \mathrm{C}$ for 18 hours to perform the antimicrobial

susceptibility test. After that, the tubes were stored at $-80{ }^{\circ} \mathrm{C}$.

Antimicrobial susceptibility test. We used the Kirby Bauer technique (disc diffusion

in Muller Hinton agar) to determine the strains antimicrobial susceptibility using the

following twelve antimicrobial discs: Cefazolin (CZ; $30 \mu \mathrm{g})$, Ciprofloxacin (CIP; $5 \mu \mathrm{g})$,

Ampicillin (AM; $10 \mu \mathrm{g}$ ), Chloramphenicol (C; $30 \mu \mathrm{g})$, Imipenem (IPM; $10 \mu \mathrm{g}$ ),

Trimethoprim-sulfamethoxazole (SXT; 1.25/23.75 $\mu \mathrm{g}$ ), Gentamicin (GM; $10 \mu \mathrm{g}$ ),

Ceftazidime (CAZ; $30 \mu \mathrm{g}$ ), Cefepime (FEP; $30 \mu \mathrm{g}$ ), Cefotaxime (CTX; $30 \mu \mathrm{g}$ ),

Tetracycline (TE; $30 \mu \mathrm{g}$ ) and Amoxicillin + Clavulanic Acid (AMC; 20/10 $\mu \mathrm{g}$ ).

Resistance or susceptibility was determined according to Clinical and Laboratory

Standards Institute (CLSI) guidelines [41].

DNA extraction. Each isolate was grown on MacConkey agar at $37^{\circ} \mathrm{C}$ for 18 hours and

5-6 colonies were placed into Eppendorf® tubes with $500 \mu \mathrm{l}$ of sterile distilled water and DNA was released by boiling cells suspensions for 1 minute. The quality of the

DNA was monitored by gel electrophoresis.

Strains Genotyping. The clonal relationship of the isolates was screened by amplifying and sequencing the fumC gene [21] using the Master Mix Go Taq. Those isolates coming from the same individual and sharing the same allele were subjected to full multi-locus sequence-typing (MLST). Briefly, PCR conditions were: 180 secs at $95^{\circ} \mathrm{C}$, 30 cycles of 30 secs at $94^{\circ} \mathrm{C}, 30$ secs at the annealing temperature of each primer ( $a d k$ : 
10

DNA sequencing. All PCR products were sequenced at Macrogen Inc. using the Sanger sequencing method. The sequences were analyzed using the program Geneious Prime 2020 and were screened in the Enterobase database [50].

213 Statistical analysis. Significant differences between phenotypic antimicrobial

214 resistance prevalence of the individuals through time were tested using a chi-square test.

\section{ACKNOWLEDGMENTS}

P.C. is funded by NIH FIC D43TW010540 Global Health Equity Scholars. The study the work for publication.

\section{REFERENCES}

1. Yong E. 2016. I contain multitudes: the microbes within us and grander view of Microbiol 19:1366-1378 doi:10 1111/1462-2920 13659 microbial colonizers of the human gut: composition, activities, and health implications of the infant gut microbiota. Microbiol Mol Biol Rev 8:e00036-17 
4. Tenaillon O, Skurnik D, Picard B, Denamur E, 2010. The population genetics of commensal Escherichia coli Nat Rev Microbiol 8: 207-217 doi:10 1038/nrmicro2298

5. Richter T, Michalski J, Zanetti L, Tennant S, Chen W, Rasko D. 2018. Responses of the human gut Escherichia coli population to pathogen and antibiotic disturbances. mSystems 3:e0047-18

6. Caugant, D, Levin B, Selander, R. 1981. Genetic diversity and temporal variation in the $E$ coli population of a human host Genetics 98:467-490

7. Selander R, Caugant D, Ochman H, Musser J, Gilmour M, Whittam T. 1986. Methods of multilocus enzyme electrophoresis for bacterial population genetics and systematics App Environ Microbiol 51:873-884

8. Fukami T. 2015. Historical contingency in community assembly: integrating niches, species pools, priority effects. Annu Rev Ecol Evol Syst 46:1-23

9. Faith J, Guruge J, Charbonneau M, Subramanian S, Seedorf H, Goodman A, Clemente J, Knight R, Heath A, Leibel R, Rosenbaum M, Gordon J. 2013. The long-term stability of the human gut microbiota. Science 341:1237439-1237439 doi:10 1126/science 1237439

10. Martinson J, Pinkham N, Peters G, Cho H, Heng J, Rauch M, Broadaway S, Walk S. 2019. Rethinking gut microbiome residency and the Enterobacteriaceae in healthy human adults. ISME 13:2306-2318

11. Priya S, Blekhman R. 2019. Population dynamics of the human gut microbiome: change is the only constant. Genome Biol 31:150 doi: 10.1186/s13059-019-17753.

12. Tingting J. 2019. Defining the role of individual gut commensal microbes and host-microbe interactions. Ph.D. Thesis. University of Alberta, Canada 
13. Wold A, Caugant D, Lidin-Janson G, de Man P, Svanborg C. 1992. Resident colonic Escherichia coli strains frequently display uropathogenic characteristics. J Infec Dis165:46-52 doi:10 1093/infdis/165 146

14. Escobar-Páramo P, Grenet K, Le Menac’h A, Rode L, Salgado E, Amorin C, Gouriou S, Picard B, Chérif M, Andremont A, Denamur E, Ruimy R. 2004. Large-

15. Sears H, Brownlee I, Uchiyama J. 1950. Persistence of individual strains of Escherichia coli in the intestinal tract of man. J Bacteriol 59:293-301

16. Adlerberth I, Jalil F, Carlsson B, Mellander L, Hanson L, Larsson P, Khalil K, Wold A. 1998. High turnover rate of Escherichia coli strains in the intestinal flora of infants in Pakistan. Epidemiol Infec 121:587-598

17. Kaper J, Nataro J, Mobley H. 2004. Pathogenic Escherichia coli. Nat Rev Microbiol 2:123-140 doi:10 1038/nrmicro818

18. Ritcher T, Hazen T, Lam D, Coles J, Seidman J, You Y, Silbergeld E, Fraser C, Rasko D. 2018. Temporal variability of Escherichia coli diversity in the gastrointestinal tracts of Tanzanian children with and without exposure to antibiotics. mSphere 3:e00558-18 doi:10 1128/msphere 00558-18

19. Delmas J, Dalmasso G, Bonnet R. 2015 Escherichia coli: The good, the bad, and the ugly. Clin Microbiol Open Access. 4:2 doi:10 4172/2327-5073 1000195

20. Gordo I, Demengeot J, Xavier K. 2014 Escherichia coli adaptation to the gut environment: a constant fight for survival Future Microbiol 9:1235-1238 doi:10 2217/fmb 1486 
21. Barrera S, Cárdenas P, Graham J, Trueba G. 2018. Changes in dominant Escherichia coli and antimicrobial resistance after $24 \mathrm{hr}$ in fecal matter. MicrobiologyOpen e00643 doi:10 1002/mbo3 643

22. Gumpert H. 2014. Dynamics of co-existing Escherichia coli lineages in situ of Denmark

23. Courvalin P. 2016. Why is antibiotic resistance a deadly emerging disease?. Clin Microbiol Infec 22:405-407 doi:10 1016/j cmi 201601012

24. Reygaert W. 2018. An overview of the antimicrobial resistance mechanisms of bacteria AIMS Microbiol 4:482-501 doi: 10 3934/microbiol 20183482

25. Ramberg S. 2016. Tracking population dynamics of $E$ coli strains in a healthy human infant over the first year of life. Master's Thesis. University of Oslo, Norway

26. Lautenbach E, Bilker W, Tolomeo P, Maslow J. 2008. Impact of diversity of colonizing strains on strategies for sampling Escherichia coli from fecal specimens J Clin Microbiol 46:3094-3096 doi:10 1128/jcm 00945-08

27. Gordon D, O’Brien C, Pavli P. 2015. Escherichia coli diversity in the lower intestinal tract of humans. Environ Microbiol Reports. 7:642-648 doi:10 $1111 / 1758-222912300$

28. World Health Organization. 2018. Antibiotic Resistance (www who int/newsroom/fact-sheets/detail/antibiotic-resistance)

29. Levin B, Lipsitch M, Perrot V, Schrag S, Antia R, Simonsen L, Moore N, Stewart F. 1997. The population genetics of antibiotic resistance. Clin Infec Dis 24: S9S16 
14

30. Salinas L, Cárdenas P, Johnson T, Vasco K, Graham J, Trueba G. 2019. Diverse commensal Escherichia coli and plasmids disseminate antimicrobial resistance genes in odmestic animals and children in a semirural community in Ecuador. mSphere 4:e00316-19 doi:10 1128/msphere 00316-19

31. Vasco K, Graham JP, rueba G. 2016 Detection of zoonotic enteropathogens in children and domestic animals in a semirural community in Ecuador. App Environ Microbiol 82:4218-4224 doi:10 1128/aem 00795-16

32. Collignon P, Beggs J, Walsh T, Gandra S, Laxminarayan R. 2018. Anthropological and socioeconomic factors contributing to global antimicrobial resistance: a univariate and multivariable analysis. Lancet Planet Health 2:e398e405 doi:10 1016/s2542-5196(18)30186-4

33. Rousham E, Unicomb L, Islam M. 2018. Human, animal and environmental contributors to antibiotic resistance in low-resource settings: integrating behavioural epidemiological and One Health approaches. Proc Biol Sci 285:20180332 285(1876)

34. Montealegre M, Talavera A, Roy S, Iqbal M, Aminul M, Lanza V, Julian T. 2020. High genomic diversity and heterogenous origins of pathogenic and antibiotic-resistant Escherichia coli in household settings represent a challenge to reducing transmission in low-income settings. mSphere 5:e00704-19

35. Brito I, Yilmaz S, Huang K, Xu L, Jupiter S, Jenkins A, Naisilisili W, Tamminen M, Smillie C, Wortman J, Birren B, Xavier R, Blainey P, Singh A, Gevers D, Alm E. 2016. Mobile genes in the human microbiome are structured from global to individual scales. Nature 535:435-439 doi:10 1038/nature18927 
36. Cloeckaert A, Stanislas M, Doublet B. 2017. Editorial: genetics of acquired antimicrobial resistance in animal and zoonotic pathogens. Front Microbiol 8:2428 doi:10 3389/fmicb 201702428

37. Nicolas M, Bertrand X, Madec J. 2014. Escherichia coli ST131, an intriguing clonal group. Clin Microbiol Rev 27:543-574 doi:10 1128/cmr 00125-13

38. Reid C, DeMaere M, Djordjevic S. 2018. Australian porcine clonal complex 10 (CC10) Escherichia coli belong to multiple sublineages of a highly diverse global

39. Yamaji R, Rubin J, Thys E, Friedman C, Riley L. 2018. Persistent pandemic CC10 phylogeny. Microb Genom 5:e000225 doi: 10 1099/mgen 0000225 lineages of uropathogenic Escherichia coli in a college community from 1999 to 2017. J Clin Microbiol 56:e01834-17 doi:10 1128/jcm 01834-17

40. Pietsch M, Irrgang A, Roschanski N, Brenner G, Hamprecht A, Rieber H, Käsbohrer A, Schwarz S, Rösler U, Kreienbrock L, Pfeifer Y, Fuchs S, Werner G, RESET Study Group. 2018. Whole genome analyses of CMY-2-producing Escherichia coli isolates from humans, animals and food in Germany. BMC Genomics 19:601.

41. Clinical and Laboratory Standards Institute Performance Standards for Antimicrobial Susceptibility Testing $201828^{\text {th }}$ Ed CLSI supplement M100

42. Gibbons S, Kearney S, Smillie C, Alm E. 2017. Two dynamic regimes in the human gut microbiome. PLoS Comput Biol 13:e1005364. doi:10 1371/journal pcbi 1005364

43. Donaldson G, Lee S, Mazmanian S. 2015. Gut biogeography of the bacterial microbiota. Nat Rev Microbiol 14:20-32. doi:10 1038/nrmicro3552

44. Shapiro BJ. 2016. How clonal are bacteria over time?. Curr Opin Microbiol 31:116-123 doi:10 1016/j mib 201603013 
45. Vracken G. 2019. Synthetic ecology of the human gut microbiota. Nat Rev Microbiol 17: 54-763 doi: 10 1038 / s41579-019-0264-8

46. Selzer P, Marhöfer R, Koch .2018. Applied Bioinformatics 2nd Ed Springer

47. Sonda T, Kumburu H, van Zwetselaar M, Alifrangis M, Mmbaga B, Aarestrup F, Kibiki G, Lund O. 2018. Whole genome sequencing reveals high clonal diversity of Escherichia coli isolated from patients in a tertiary care hospital in Moshi,

48. Davies N, Flasche S, Jit M, Atkins K. 2019. Within-host dynamics shape antibiotic resistance in commensal bacteria. Nat Ecol Evo 3:440-449. doi:10 1038/s41559-018-0786-X

49. Kerr B, Riley M, Feldman M, Bohannan B. 2002. Local dispersal promotes biodiversity in a real-life game of rock-paper-scissors. Nature 418:171-174 doi:10 1038/nature00823

50. Zhou Z, Alikhan N, Mohamed K. 2020. The EnteroBase user's guide with case studies on Salmonella transmissions Yersinia pestis phylogeny and Escherichia core genomic diversity http://enterobase warwick ac uk/

51. Schlager TA, Hendley JO, Bell AL, Whittam TS. 2002. Clonal diversity of Escherichia coli colonizing stools and urinary tracts of young girls. Infect Immun 70:1225-1229 doi:10 1128/iai 703 1225-1229 2002

52. Peña-Gonzalez A, Soto-Girón MJ, Smith S, Sistrunk J, Montero L, Páez M, Ortega E, Hatt JK, Cevallos W, Trueba G, Levy K, Konstantinidis KT. 2019. Metagenomic signatures of gut Infections caused by different Escherichia coli pathotypes. Appl Environ Microbiol 85(:e01820-19 
17

84

53. Fang X, Monk JM, Nurk S, Akseshina M, Zhu Q, Gemmell C, Gianetto-Hill C, Leung N, Szubin R, Sanders J, Beck PL, Li W, Sandborn WJ, Gray-Owen SD, Knight R, Allen-Vercoe E, Palsson BO, Smarr L. 2018. Metagenomics-based strain-level analysis of Escherichia coli from a time-series of microbiome samples from a Crohn's disease patient. Front Microbiol 9:2559 doi:10 3389/fmicb 2018 02559 
bioRxiv preprint doi: https://doi org/10.1101/2020.11.09.375931. this version posted November 11, 2020. The copyright holder for this preprint (which was not certified by peer review) is the author/funder, who has granted bioRxiv a license to display the preprint in perpetuity. It is made available under aCC-BY-NC-ND 4.0 International license.

18

FIG 1 Diversity of numerically dominant fecal E. coli isolates obtained during 3 sampling periods Different colors indicate different fumC alleles and ST numbers indicate strains belonging to sequence types found in different sampling periods

\begin{tabular}{|c|c|c|c|}
\hline $\begin{array}{cc}\text { Child } \\
\text {. }\end{array}$ & & 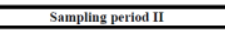 & 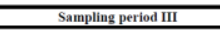 \\
\hline 1 & 0000 & 00000 & 00000 \\
\hline 2 & 00000 & 00000 & 00000 \\
\hline 3 & 00000 & 00000 & 00000 \\
\hline 4 & 00000 & 00000 & 0000 \\
\hline 5 & 00000 & 00000 & 00000 \\
\hline 6 & 00000 & 0 & N/A \\
\hline 7 & 00000 & 00000 & 0000 \\
\hline 8 & 00000 & 000 & N/A \\
\hline 9 & 0000 & 00000 & 00000 \\
\hline 10 & 00000 & 00000 & 00000 \\
\hline 11 & 00000 & 00000 & 00000 \\
\hline 12 & 00000 & 00000 & N/A \\
\hline 13 & 00000 & 00000 & 00000 \\
\hline 14 & 00000 & 00000 & N/A \\
\hline 15 & 00000 & 00000 & 00000 \\
\hline 17 & 00000 & 0000 & $\mathrm{~N} / \mathrm{A}$ \\
\hline 18 & 00000 & 00000 & N/A \\
\hline 19 & 00000 & 00000 & 00000 \\
\hline 20 & 00000 & 0000 (iii) & (iii) 000 \\
\hline 21 & 00000 & 00000 & 00000 \\
\hline 22 & 00000 & 00000 & $\mathrm{~N} / \mathrm{A}$ \\
\hline 23 & 0000 (1표 & 100(표) & 00000 \\
\hline 24 & 00000 & 00000 & 0000 \\
\hline 25 & 00000 & 00000 & 00000 \\
\hline 26 & (푸) 000 & 00000 & 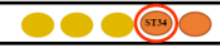 \\
\hline 27 & 00000 & 00000 & 00000 \\
\hline 28 & 00000 & 00000 & N/A \\
\hline 29 & 00000 & 00000 & 00000 \\
\hline 30 & 1000 & (파) 000 & 00000 \\
\hline 31 & 00000 & 00000 & 00000 \\
\hline
\end{tabular}


TABLE 1 Antimicrobial susceptibility profiles of $E$. coli isolates obtained from children (fecal samples) in different sampling periods (SPI, SPII, SPIII).

\begin{tabular}{|c|c|c|c|c|c|}
\hline \multirow[b]{2}{*}{ Antimicrobials } & \multicolumn{3}{|c|}{$\mathrm{n}=110$ isolates (each one) } & \multirow[b]{2}{*}{$\begin{array}{c}\text { Chi square } \\
\text { test }\end{array}$} & \multirow[b]{2}{*}{$P$ value } \\
\hline & SP I & SP II & SP III & & \\
\hline Ampicillin (AM) & $64(58.2 \%)$ & $60(54.5 \%)$ & $46(41.8 \%)$ & 6.502 & 0.039 \\
\hline Chloramphenicol (C) & $5(4.5 \%)$ & $12(10.9 \%)$ & $9(8.2 \%)$ & 3.090 & 0.213 \\
\hline Imipenem (IPM) & $12(10.9 \%)$ & 1 (0.9 \%) & $7(6.4 \%)$ & 9.687 & 0.008 \\
\hline Trim-sulfamet (SXT) & $58(52.7 \%)$ & $58(52.7 \%)$ & $50(45.4 \%)$ & 1.552 & 0.460 \\
\hline Gentamicin (GM) & $0(0 \%)$ & $6(5.4 \%)$ & $0(0 \%)$ & & \\
\hline Ceftazidime (CAZ) & $2(1.8 \%)$ & $14(12.7 \%)$ & $10(9.1 \%)$ & 9.352 & 0.009 \\
\hline Cefepime (FEP) & $13(11.8 \%)$ & $15(13.6 \%)$ & $9(8.2 \%)$ & 1.705 & 0.426 \\
\hline Cefazolin (CZ) & $18(16.4 \%)$ & $14(12.7 \%)$ & $15(13.6 \%)$ & 0.645 & 0.724 \\
\hline Ciprofloxacin (CIP) & $22(20 \%)$ & $21(19.1 \%)$ & $9(8.2 \%)$ & 7.168 & 0.028 \\
\hline Cefotaxime (CTX) & $14(12.7 \%)$ & $18(16.4 \%)$ & $14(12.7 \%)$ & 0.808 & 0.668 \\
\hline Amoxicillin + Clav. Ac.(AMC) & 35 (31.8 \%) & $28(25.4 \%)$ & 15 (13.6\%) & 10.376 & 0.006 \\
\hline Tetracycline (TE) & $55(50 \%)$ & $52(47.3 \%)$ & $50(45.4 \%)$ & 0.462 & 0.794 \\
\hline
\end{tabular}

$(P$ value $<0.05)$ 


\begin{tabular}{|c|c|c|c|}
\hline 1 & 0000 & 00000 & 00000 \\
\hline 2 & 00000 & 00000 & 00000 \\
\hline 3 & 00000 & 00000 & 00000 \\
\hline 4 & 00000 & 00000 & 00000 \\
\hline 5 & 00000 & 00000 & 00000 \\
\hline 6 & 00000 & 0 & N/A \\
\hline 7 & 00000 & 00000 & 00000 \\
\hline 8 & 00000 & 000 & $\mathrm{~N} / \mathrm{A}$ \\
\hline 9 & 00000 & 00000 & 00000 \\
\hline 10 & 00000 & 00000 & 00000 \\
\hline 11 & 00000 & 00000 & 00000 \\
\hline 12 & 00000 & 00000 & N/A \\
\hline 13 & 00000 & 00000 & 00000 \\
\hline 14 & 00000 & 00000 & N/A \\
\hline 15 & 00000 & 00000 & 00000 \\
\hline 17 & 00000 & 00000 & N/A \\
\hline 18 & 00000 & 00000 & $\mathrm{~N} / \mathrm{A}$ \\
\hline 19 & 00000 & 00000 & 00000 \\
\hline 20 & 00000 & 0000 (im) & (ii) 0000 \\
\hline 21 & 00000 & 00000 & 00000 \\
\hline 22 & 00000 & 00000 & N/A \\
\hline 23 & 0000 (iin) & 000 (iii) & 00000 \\
\hline 24 & 00000 & 00000 & 00000 \\
\hline 25 & 00000 & 00000 & 00000 \\
\hline 26 & (ii2) 0000 & 00000 & 0000 \\
\hline 27 & 00000 & 00000 & 00000 \\
\hline 28 & 00000 & 00000 & $\mathrm{~N} / \mathrm{A}$ \\
\hline 29 & 00000 & 00000 & 00000 \\
\hline 30 & 00 (iii) 00 & (iii) 0000 & 00000 \\
\hline 31 & & & \\
\hline
\end{tabular}

Every circle represent an $E$.coli isolate.

The red circles represent those possible resident isolates. 